\title{
FAMILY ADVERSITY FACTORS AND EXTERNAL RESOURCES OF RESILIENCE IN A ONE-YEAR FOLLOW-UP
}

\author{
Lenka Abrinková ${ }^{1}$, Ol'ga Orosová ${ }^{2}, \&$ Maria Bacikova-Sleskova ${ }^{2}$ \\ ${ }^{1}$ Department of Psychology, PJ Safarik University in Kosice (Slovakia) \\ ${ }^{2}$ Department of Educational Psychology and Psychology of Health, PJ Safarik University in Kosice
}

(Slovakia)

\begin{abstract}
Objectives: External resources of resilience along with internal assets facilitate the healthy development of adolescents and eventually contribute to overcoming adversity. Therefore, it is crucial to examine the factors which enhance or reduce external resources of resilience. The main goal of this study is to explore the role of adversity factors: adolescents - parental conflict, antagonism and punishment and family structure in explaining perceived external resources of resilience - school meaningful participation and community meaningful participation in a one-year follow-up.

Methods: $146(49 \%$ girls) adolescents (T1 mean age=13.51) participated in a repeated measures design with a 12-month follow-up. External resources of resilience (School meaningful participation (SMP) and Community meaningful participation (CMP)) were measured by the RYDM questionnaire. Parental conflict, antagonism and punishment were assessed by the NRI-SPV questionnaire separately for the mother and father. The family structure was dichotomized (both biological parents vs. other).

Results: The linear regression revealed that having something other than biological family is associated with lower SMP and CMP over the year while controlling for SMP and CMP at T1. Moreover, higher punishment from the father is associated with lower SMP while higher antagonism with the mother is associated with higher CMP after one year. In addition, the findings confirmed a moderation effect of gender and father punishment on SMP. This shows that the probability of lower SMP at T2 is higher for boys with a higher level of punishment by the father at T1.

Conclusion: Family structure is a key factor in contributing to lower external resources of resilience. Father punishment negatively contributes to SMP, although not CMP. Mother antagonism positively contributes to CMP but not SMP. The moderation effect of gender between father punishment and SMP implies a greater sensitivity of boys towards father punishment and a potential inhibition effect on participation at school in comparison to girls. Interestingly, antagonism with the mother contributes to higher CMP which reveals the potential self-protection mechanism of adolescents in compensating antagonism with the mother for meaningful participation in different environments such as the community. However, there is a failure to compensate at school when the punishment from the father is greater.
\end{abstract}

Keywords: External resilience, family adversity, adolescents.

\section{Introduction}

Adolescents from disadvantaged, dysfunctional or impaired home environments are more at risk of negative outcomes such as mental illnesses (Hughes et al., 2018), substance use (Pilowsky et al., 2009) or low life satisfaction (Levin et al., 2012). Moreover, this is not only in adolescence but can continue into adulthood. Initial research (Antonovsky, 1979; Werner \& Smith, 1982) has confirmed that the relationship between adversity and negative outcomes is not direct. The existence of resilience factors that mediate or moderate the adversity and negative outcomes has been confirmed (Masten, 2014). However, less is known about how family adversity factors affect various resilience factors. Few studies have addressed home adversity factors such as parenting style, socioeconomic status, divorce/separation, abuse, parental disabilities which are negatively associated with internal assets and external resources of resilience such as: self-esteem (Zilioli et al., 2016), self-control (Ng-Knight \& Schoon, 2017), meaningful activities (Garmienė, Žemaitienė \& Zaborskis, 2006; Flynn et al., 2006) or relationships with others (Merz \& Jak, 2013). There is also a research gap regarding longitudinal research. Thus, this current study aimed to explore whether specific family factors explain perceived external resources of resilience over a year. 


\section{Design}

A repeated measure design was used.

\section{Objectives}

The objective of this study was to examine the role of family adversity factors: adolescents - parental conflict, antagonism, punishment and family structure in explaining perceived external resources of resilience - school meaningful participation and community meaningful participation in a one-year follow-up.

\section{Methods}

\subsection{Sample and procedure}

The data were collected in two repeated measure design study with a baseline (T1) and a 12-month follow-up (T2) in 6 randomly selected Slovak primary schools. All seventh-grade students from every school participated in the research. The sample consisted of 146 (49\% girls) adolescents (mean age $=13.51$ at $\mathrm{T} 1)$.

\subsection{Measures}

The adolescents were asked to fill in a paper version of the questionnaire regarding their relationship with parents, their family structure and perceived external resources of resilience (school and community meaningful participation). Participation in the study was anonymous and voluntary.

- External resources of resilience were explored using the RYDM (Resilience and Youth Development Module) (Constantine, Benard and Diaz 1999) questionnaire with 4-point Likert-type responses ( $1=$ not true at all, $4=$ very much true).

○ school meaningful participation $(\mathrm{CA}=0.67)$ : “At school I help decide things like class activities or rules"

○ community meaningful participation $(\mathrm{CA}=0.93)$ "Outside of my home and school, I do these things: I am part of clubs, sports teams, church/temple, or other group activities "

- Family adversity factors were explored using the NRI-SPV (The Network of Relationship Social Provision Version) (Furman \& Buhrmester, 1985) questionnaire with 5-point Likert-type responses $(1=$ not at all or little, $5=$ most of the time) separately for the mother and father.

○ conflict (mother $\mathrm{CA}=0.77$; father $\mathrm{CA}=0.76$ ): "How much do you and this person get upset with or mad at each other?"

○ antagonism (mother $\mathrm{CA}=0.70$; father $\mathrm{CA}=0.69$ ): "How much do you and this person hassle or nag one another?"

○ punishment (mother $\mathrm{CA}=0.75$; father $\mathrm{CA}=0.81$ ): "How often does this person punish you?")

Family structure was assessed using 4 separate items exploring the composite of the child's home environment by the question ,Which of the following people live in the same household with you?" with possible answers: mother, father, stepmother, stepfather. We dichotomized the variables into: 0 - biological family (mother and father present in household) or 1 - others (one of the parents is absent or there is the presence of a step-parent)

\subsection{Statistical analyses}

Two separate linear regression models were used to assess the association between family adversity factors and external resources of resilience over one year. School meaningful participation and community meaningful participation at T2 served as the dependent variables while family adversity factors at $\mathrm{T} 1$ served as the independent variables. The models were controlled for the effect of resilience in T1. A T-test and Chi-square test were performed to assess the gender differences in all variables. In order to assess the potentially different effects in gender, all interactions with gender were tested.

\subsection{Results}

The descriptive analysis and gender differences in all explored variables are presented in Table 1. Generally, external resources of resilience were higher among girls with significant gender differences in community meaningful participation at T1 while negative interactions with parents (conflict, antagonism) and parental punishment was higher among boys with significant gender differences in father punishment. Gender differences in family structure were not found. 
Table 1. The descriptive characteristics in the measured variables according to gender.

\begin{tabular}{|l|l|l|l|l|}
\hline VARIABLE & $\begin{array}{l}\text { BOYS } \\
\text { Mean }(\mathrm{SD})\end{array}$ & $\begin{array}{l}\text { GIRL } \\
\text { Mean }(\mathrm{SD})\end{array}$ & T value & Sig \\
\hline T1 School meaningful participation & $2.35(\mathrm{SD}=0.77)$ & $2.56(\mathrm{SD}=0.77)$ & -1.90 & $\mathrm{~ns}$ \\
\hline T2 School meaningful participation & $2.28(\mathrm{SD}=0.82)$ & $2.49(\mathrm{SD}=0.80)$ & -1.80 & $\mathrm{~ns}$ \\
\hline T1 Community meaningful participation & $2.75(\mathrm{SD}=0.98)$ & $3.27(\mathrm{SD}=0.70)$ & -4.29 & $<.01$ \\
\hline T2 Community meaningful participation & $2.28(\mathrm{SD}=0.82)$ & $2.49(\mathrm{SD}=0.80)$ & -1.75 & $\mathrm{~ns}$ \\
\hline T1 Father conflict & $2.00(\mathrm{SD}=0.95)$ & $1.81(\mathrm{SD}=0.72)$ & 1.54 & $\mathrm{~ns}$ \\
\hline T1 Father antagonism & $1.99(\mathrm{SD}=0.95)$ & $1.86(\mathrm{SD}=0.79)$ & 1.01 & $\mathrm{~ns}$ \\
\hline T1 Father punishment & $2.53(\mathrm{SD}=1.07)$ & $2.23(\mathrm{SD}=0.89)$ & 2.00 & $<.05$ \\
\hline T1 Mother conflict & $2.00(\mathrm{SD}=0.85)$ & $2.03(\mathrm{SD}=0.88)$ & -0.24 & $\mathrm{~ns}$ \\
\hline T1 Mother antagonism & $1.94(\mathrm{SD}=0.89)$ & $1.83(\mathrm{SD}=0.80)$ & 0.92 & $\mathrm{~ns}$ \\
\hline T1 Mother punishment & $2.49(\mathrm{SD}=0.96)$ & $2.34(\mathrm{SD}=0.94)$ & 1.09 & $\mathrm{~ns}$ \\
\hline T1 Family structure* & $74,7 \%$ & $69,2 \%$ & 0.70 & $\mathrm{~ns}$ \\
\hline
\end{tabular}

$\mathrm{SD}$ - Standard deviance; *biological family is presented; the Chi-square test was used; ns - not significant

Mother antagonism at $\mathrm{T} 1$ and family structure at $\mathrm{T} 1$ were significantly associated with community meaningful participation in T2. Having both biological parents and higher mother antagonism positively contributes to higher community meaningful participation over one year.

Table 2. Regression model for community meaningful participation regarding family adversity factors.

\begin{tabular}{|c|c|c|c|c|c|}
\hline \multicolumn{6}{|c|}{ T2 Community meaningful participation $\left(R^{2}=0.40\right)$} \\
\hline Predictors & $\mathrm{B}$ & S.E. & $\beta$ & $\mathrm{t}$ & Sig \\
\hline T1 Community meaningful participation & 0.56 & 0.07 & 0.53 & 7.22 & $<.01$ \\
\hline Gender* & -0.03 & 0.14 & -0.01 & -0.21 & ns \\
\hline T1 Family structure & -0.57 & 0.15 & -0.27 & -3.71 & $<.01$ \\
\hline T1 Father conflict & 0.23 & 0.14 & 0.20 & 1.58 & ns \\
\hline T1 Father antagonism & -0.09 & 0.14 & -0.08 & -0.61 & ns \\
\hline T1 Father punishment & -0.07 & 0.12 & -0.07 & -0.58 & ns \\
\hline T1 Mother conflict & -0.10 & 0.14 & -0.10 & -0.69 & ns \\
\hline T1 Mother antagonism & 0.33 & 0.14 & 0.33 & 2.24 & $<.05$ \\
\hline T1 Mother punishment & -0.14 & 0.13 & -0.15 & -1.09 & ns \\
\hline
\end{tabular}

Note: * boys as a reference group; ns - not significant

Father punishment at T1 and family structure at T1 were significantly associated with school meaningful participation at T2. Having both biological parents positively contributes to higher school meaningful participation over one year while higher father punishment negatively contributes to school meaningful participation over one year.

Table 3. Regression model for school meaningful participation regarding family adversity factors.

\begin{tabular}{|c|c|c|c|c|c|}
\hline \multicolumn{6}{|c|}{ T2 School meaningful participation $\left(\mathrm{R}^{2}=0.39\right)$} \\
\hline Predictors & $\mathrm{B}$ & S.E. & $\beta$ & $\mathrm{t}$ & Sig. \\
\hline T1 School meaningful participation & 0.45 & 0.07 & 0.46 & 6.26 & $<.01$ \\
\hline Gender* & -0.46 & 0.32 & -0.29 & $-1,42$ & ns \\
\hline T1 Family structure & -0.36 & 0.13 & -0.20 & -2.69 & $<.01$ \\
\hline T1 Father conflict & 0.03 & 0.12 & 0.03 & 0.24 & ns \\
\hline T1 Father antagonism & 0.21 & 0.13 & 0.21 & 1.60 & ns \\
\hline T1 Father punishment & -0.58 & 0.19 & -0.73 & -2.97 & $<.01$ \\
\hline T1 Mother conflict & 0.07 & 0.13 & 0.08 & 0.56 & ns \\
\hline T1 Mother antagonism & -0.79 & 0.13 & -0.08 & -0.59 & ns \\
\hline T1 Mother punishment & -0.08 & 0.11 & -0.10 & -0.72 & ns \\
\hline Gender * Father punishment & 0.28 & 0.12 & 0.59 & 2.24 & $<.05$ \\
\hline
\end{tabular}

Note: * boys as the reference group; ns - not significant

Regarding the moderation effect, the relationship between father punishment and school meaningful participation varies depending on gender. Boys with high father punishment show a higher probability of low school meaningful participation compared to girls with high father punishment. Thus, it seems that gender moderates the relationship between father punishment and school meaningful participation. This can be seen in Figure 1. The moderation effects of other variables were tested but were insignificant and thus are not displayed. 
Figure 1. Interaction effect of gender and father punishment at T1.

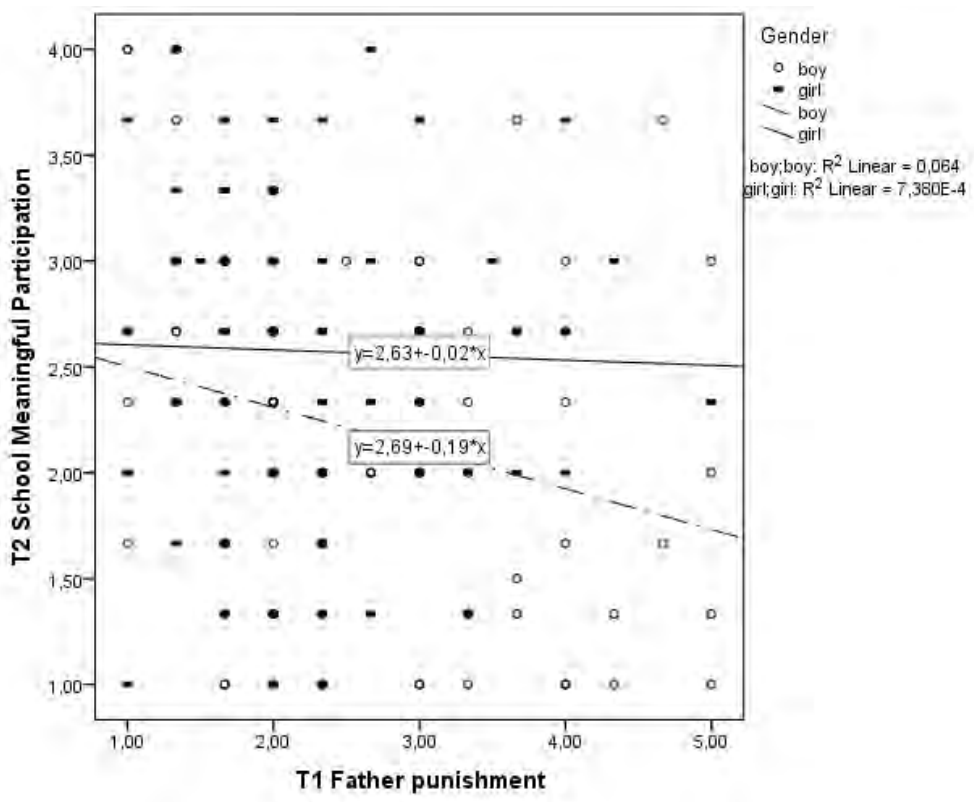

\section{Discussion and conclusion}

The findings of this study show that family adversity factors play an important role in perceived external resources of resilience over a year among adolescents. Moreover, a moderation effect of gender on the relationship between father punishment and school meaningful participation was found.

In our study, mother antagonism was found to be positively associated with higher community meaningful participation after one year. The possible self-protective mechanism could activate a healthy way of how to compensate the negative relationship with the mother, through meaningful participation in a different environment such as the community. Gauze et al. (1996) states that adolescents are "active consumers of social support" who can turn to different relationships if the other is not providing efficient support. Thus, we can extend these findings regarding social support and apply them to broader social contexts by hypothesizing that higher negative experiences in one's environment is compensated by seeking positive experiences in others. However, this possible self-protective mechanism is not effective regarding father punishment (punishment in general, verbal aggression with insults, harsh criticism) which was found to be negatively associated with school meaningful participation. It seems that negative interaction such as antagonism with the mother has an activation effect on adolescents while punishment, a highly negative experience especially with the father, may inhibit responses other than the one being punished. Adolescents who are punished may become withdrawn, inhibited and less activated than others (Mhlongo, 2013). Thus, adolescents may be inhibited to seek healthy compensation as in the case when antagonism with the mother is experienced.

Moreover, the moderation effect of gender between father punishment and school meaningful participation revealed that boys who experience father punishment score less regarding school meaningful participation compared to girls who experience father punishment. It is well-known that girls are more social, active and involved in school activities, rule-setting or voluntary activities than boys (Villaruel et al., 2003). Thus, father punishment may have a less negative effect on their school meaningful participation compared to boys. The results from Table 1 show that girls score higher in meaningful participation not only in the school environment but also in the community with significant gender differences. This supports the claim that it is easier for girls to meaningfully participate in the environment.

Family structure was significantly associated with external resources of resilience. Having both biological parents positively contributes to school and community meaningful participation as well as to overall positive youth development (Levin et al., 2012). There may be several reasons for assuming that family structure has an effect on children's meaningful participation. Firstly, the income of single parent families (usually mothers) can get in the way of participating in the environment. Secondly, parents are a great source of social capital, emotional support and everyday assistance. Adolescents from single parent families have lower access to social capital in comparison with two-parent households (Amato et al.,2015) and therefore are less active in their environment. It seems that stepfamilies may be more stable for adolescents although most adolescents currently living with a step-parent may have experienced 
the disruption of the original family and additional transition to a new family structure followed by potential instability or turbulences within the family. This could again contribute to a lower level of activity, even the accessibility of meaningfully participating in the environment.

In conclusion, it is important to foster meaningful participation in both the school and community environment. It is also necessary to pay attention to unhealthy relationships in families and protect children due to the impact not only on negative youth development outcomes but also on external resources of resilience despite the potential compensation mechanism.

\section{Acknowledgements}

This work was supported by Research and Development support Agency under the contract No. APVV-15-0662.

\section{References}

Amato, P. R., Patterson, S., \& Beattie, B. (2015). Single-parent households and children's educational achievement: A state-level analysis. Social science research, 53, 191-202.

Antonovsky, A. (1979). Health, stress, and coping. San Francisco, CA: Jossey-Bas

Constantine, N., Benard, B., \& Diaz, M. (1999, June). Measuring protective factors and resilience traits in youth: The healthy kids resilience assessment. In seventh annual meeting of the Society for Prevention Research, New Orleans, LA (pp. 3-15)

Flynn, R. J., Dudding, P. M., \& Barber, J. G. (Eds.). (2006). Promoting resilience in child welfare. University of Ottawa Press

Furman, W., \& Buhrmester, D. (1985). Children's perceptions of the personal relationships in their social networks. Developmental psychology, 21(6), 1016

Garmienè, A., Žemaitienè, N., \& Zaborskis, A. (2006). Family time, parental behaviour model and the initiation of smoking and alcohol use by ten-year-old children: an epidemiological study in Kaunas, Lithuania. BMC Public Health, 6(1), 287

Gauze, C., Bukowski, W. M., Aquan-Assee, J., \& Sippola, L. K. (1996). Interactions between family environment and friendship and associations with self-perceived well-being during early adolescence. Child development, 67(5), 2201-2216.

Hughes, K., Ford, K., Davies, A. R., Homolova, L., \& Bellis, M. A. (2018). Sources of resilience and their moderating relationships with harms from adverse childhood experiences. Cardiff: Public Health Wales

Levin, K. A., Dallago, L., \& Currie, C. (2012). The association between adolescent life satisfaction, family structure, family affluence and gender differences in parent-child communication. Social Indicators Research, 106(2), 287-305

Masten, A. S. (2014). Global perspectives on resilience in children and youth. Child development, 85(1), 6-20

Merz, E. M., \& Jak, S. (2013). The long reach of childhood. Childhood experiences influence close relationships and loneliness across life. Advances in life course research, 18(3), 212-222

Ng-Knight, T., \& Schoon, I. (2017). Disentangling the influence of socioeconomic risks on children's early self-control. Journal of personality, 85(6), 793-806.

Pilowsky, D. J., Keyes, K. M., \& Hasin, D. S. (2009). Adverse childhood events and lifetime alcohol dependence. American journal of public health, 99(2), 258-263.

Villarruel, F. A., Perkins, D. F., Borden, L. M., \& Keith, J. G. (Eds.). (2003). Community youth development: Programs, policies, and practices. Sage.

Werner, E.E. \& Smith, R.S. (1982). Vulnerable, but invincible: a longitudinal study of resilient children and youth. New York City, NY: McGraw-Hill

Zilioli, S., Slatcher, R. B., Chi, P., Li, X., Zhao, J., \& Zhao, G. (2016). Childhood adversity, self-esteem, and diurnal cortisol profiles across the life span. Psychological science, 27(9), 1249-1265. 